\title{
PERSPECTIVES ON TEACHING BIOSTATISTICS FOR UNDERGRADUATE MEDICAL STUDENTS USING TEAM-BASED LEARNING
}

\author{
Ângela Tavares Paes \\ Federal University of São Paulo, Brazil \\ atpaes@unifesp.br
}

Health professions educators are constantly challenged to find out new strategies to motivate students and keep them interested in Statistics. Recently, some medical schools have adopted a methodology called team-based learning (TBL) which combines individual and small-groups learning in an interesting way. On one hand, TBL seems to be very attractive since it encourages students to develop new skills, formulate and answer questions and create opportunities of understanding the statistical concepts through real-world problems. On the other hand, TBL methodology requires a well-planned strategy and teacher/faculty preparation. Also, students have to be prepared. Implementation of TBL is not only a teacher's decision but a collaborative work. The purpose of this paper is to present some examples of activities based on TBL which can be explored and discuss critically advantages and disadvantages of the method.

\section{INTRODUCTION}

It is well known that, in general, medical students dislike and have bad performance in courses involving numeracy, especially Statistics. Even when the performance is good, the connection between theoretical statistical concepts and its applicability in Medicine is not understood. The problem begins when the student is introduced to Statistics through an introductory graduate discipline. Most of medical schools in Brazil includes statistical courses only in the first two years, when students are not interested and are not aware that it will be useful and necessary in their professional life, even outside an academic career. In addition, many of these courses are still based exclusively on traditional exposure lectures, a model that has long been considered inefficient by educators of different areas.

Medical education is always changing and educators are frequently required to rethinking and restructure their approaches. According to national guidelines for the medicine courses (Brasil, 2014) the student must have critical thinking in interpretation of data and use scientific evidences for clinical decisions. These evidences are usually based on results of statistical analysis, therefore teach Statistics in a traditional way focused on mechanics of statistical techniques without practical examples is not efficient nor motivating for medical students. Statistical courses must be reformulated and one of the most challenges is to create courses with emphasis on interpretation and applications, without loss in the learning of the theory.

With the aim of contextualize learning about Biostatistics, some new teaching initiatives has been proposed such as problem-based learning (PBL) approach (Boyle, 1999), which uses cases or problems as starting points to learn about a subject. Recently, an increasing number of medical schools have adopted a methodology called team-based learning (TBL) which combines individual and small-groups learning in an interesting way. In Brazil, TBL is even more recent and unknown among most of teachers, especially Statistics teachers. The propose of this paper is not present TBL as an unique solution, but discuss the possibility of implement it in a statistics course for undergraduate medical students. We first briefly describe TBL, then present some considerations related to statistical concepts and finally discuss the applicability, advantages and disadvantages of the method in comparison to other education strategies.

\section{A BRIEF OVERVIEW OF TEAM BASED LEARNING}

Team-based learning (TBL) is an educational strategy developed by Larry Michaelsen in the late 1970s for business course students in The University of Oklahoma. The method has gained popularity in medical education in recent years and has been implemented in many medical schools in the United States, Canada and other countries (Michaelsen, et. al, 2008). The purpose of this method is to create opportunities of the students to develop skills, acquire and apply knowledge through activities including individual work and teamwork. It can be used in large or small classes divided in multiple small groups in a single classroom. One differential from other methods is that

In: M.A. Sorto (Ed.), Advances in statistics education: developments, experiences and assessments. Proceedings of the Satellite conference of the International Association for Statistical Education (IASE), July 2015, Rio de Janeiro, Brazil. 
TBL induces the student to previous (pre-class) individual preparation and teacher can share responsibilities with them regarding to evaluation. The students are not instructed about how to work in groups, they develops collaborative work as the TBL sessions occur.

The first step is to assign students in 5-7 students groups. The groups must be formed in order to have heterogeneity within groups and homogeneity between groups. The variability between subjects can take into account gender, age, previous course work, etc. Each group should contain students who have potential to give a significant contribution to learning process and students with greater difficulty in learning. The instructor can decide his/her sorting criteria. The simplest way to choice the groups is, for example, to put the students in alphabetic order and assign one number between 1 and $\mathrm{x}$ (where $\mathrm{x}$ is the maximum number of groups defined according to class size). Instead of alphabetic order, other characteristics can be used depending on their influence on the learning about the subject.

Once small teams are defined, the instructor inform the topic to be explored and the objectives for unit. For example, "at the end of this unit the student must be able to identify (or classify) types of variables in a study and suggest methods to summarize them".

TBL consists of repeating sequences of 3 phases: 1.preparation (pre-class), 2. readiness assurance and 3. application of course concepts. In Phase 1, learners study independently outside of class to be aware about the theory and the desired objectives of the proposed activity. Phase 2 is performed in-class. First the students are submitted to a brief individual multiple-choice exam to assure their readiness to apply Phase 1 knowledge. This test is called individual readiness assurance test (iRAT). Then they re-take the same exam in group giving their consensus answers (a short time is given to share individual answers and choice the group answer). This is denominated as group readiness assurance test ( $g R A T$ ). When groups have decided their answers, the instructor provide them an instrument to be filled called Immediate feedback assessment technique (IF AT) ,where the teams have to choose one of four (or five) covered boxes, each one corresponding to an alternative of the iRAT and gRAT questions. The box with the correct answer has a mark, if the group choose this box for the first time have a score of 4 (or 5) points. Otherwise, they can try again but the score are reduced with each unsuccessful try. If the students disagree of the answer defined as correct, they can argue explaining the reasons and suggest other correct answer based on a bibliography. This appeal can be evaluated by the instructor in-class or in the next meeting. At the end of this phase, the instructor gives for the entire group a brief and focused review about the topic with relevant considerations discussed during the readiness assurance process $(R A P)$ in order to clarify concepts and give feedback for all student simultaneously. Phase 3 is called Team Application (tAPP) and consists to apply concepts to solve problems, using Phase 1 and 2 knowledge. This must be the longer phase and can be repeated until the learning has been consolidated. According to Michaelsen et. al (2008), the proposed problem must be significant to students, all the students must work in the same problem, they have to make un specific choice and report their answers simultaneously. This sequence is known as the four S's. The knowledge acquired in the Phases 1 and 2 is used in Phase 3, which may last more than one class period. When time is finished, all groups are request to reveal their answers simultaneously for comparison and discussion. Writing problems in this phase is probably the most challenging aspect to implement TBL, because more than one correct answers can be accept depending on the teacher and student's point of view. Moreover, problems formulation must be adapted depending on student's profile and course guidelines.

Regarding to evaluation in TBL, grades are based on their individual and group performance. Also, they are submitted to a peer evaluation in which each student is required to evaluate his/her teammates about their contributions to the team performance. In this way, , the students have responsibility for evaluation and the grading system can be combined with instructor assigning weights (or percentages) for each component (iRAT, tRAT, tAPP and peer evaluation).

\section{BIOSTATISTICS COURSE IN TBL}

Implement a Biostatistics course using TBL is a big challenge, since the absorption of the theory is essential to apply it to analyze and interpret data. In particular, in the medical literature, many advanced statistical techniques are often applied, even when are not completely understood 
by practioners who use them. As a consequence, students are exposed to statistical methods too early through articles and exercises from other concurrent disciplines.

To create a TBL section we first define what we want our students to be able to do when they have finished the course or unit. This must be described in the beginning and can be showed as a bullet list with several items related to the topic or, in a general mode, to the course. In a basic statistics course it could be:

- Design a simple research, defining clearly the type of the study and the target population;

- Identify all characteristics (variables) to be observed and recognized the types of variables;

- Formulate hypotheses related to the research objectives;

- Understand the main principles of sample size calculations;

- Collect, record and organize data (built a dataset) properly for the statistical analysis;

- Conduct basic statistical analysis of clinical data by using a statistical computer software (this item includes descriptive analysis concept such as central tendency measures, variability, frequencies, tables and graphic representation of data);

- Understand differences between descriptive and inferential statistical analysis and be aware of the limitations of the statistical inference.

\section{Sample activities}

To illustrate how to built questions in a TBL session, we have chosen Hypothesis test as a topic. For this topic, we can point the objectives as "at the end of this topic the student should be able to:

- Formulate statistical hypotheses according to the research objectives;

- Describe possible errors related to making decisions;

- Understand the principles of significance, power and p-values and how it is used in clinical studies;

- Recognize the importance and the contrast between statistical significance and clinical relevance.".

An example of text to be read in the pre-class preparation could be a chapter or a section of an elementary book, for example, Section 8.5. Hypothesis Testing of the book Practical Statistics for Medical Research (Altman, 1991). We next present a simple example of question that could be included in the $i R A T$ or $g R A T$.

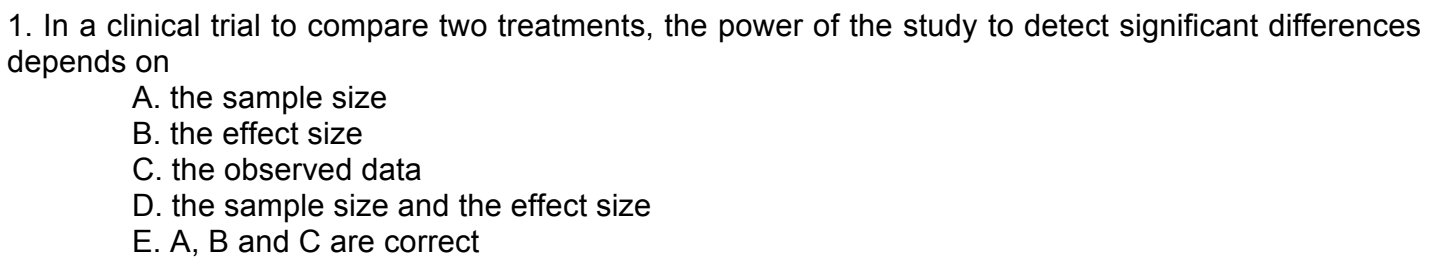

Figure 1: Sample multiple-choice question for readiness assurance tests.

The students who have read the text probably will choose the alternative $\mathrm{D}$, since there is a part of the text that says "The value of beta depends upon the size of the effect that one is interested in, and, also the sample size". However, those who have chosen the alternative E can argue they are correct because the effect size, which corresponds to the magnitude of differences between treatments in standard deviation units, can only be computed with observed data, except when it is specified during the study design. The intention of this ambiguous response is to instigate discussion among the students who will have to search for arguments to support their choices. Also, the effect size is a general denomination and the term has uncountable different definitions, depending of the source and the problem. Nowadays, students are very good internet-searchers and 
this should be considered in the quizzes creation. Medical education is changing along with technology and teachers should be prepared an adapt their methods to these changes. In this specific case, it would be useless search for effect size in the internet during the class. A brief comments with some examples and how desired effect sizes are used by researchers in the planning of studies could be done by the instructor at the end of the RAP.

Another example showed in Figure 2 was adapted from Chapter 8.5. Using p-values and confidence intervals to interpret analysis results of Kirkwood \&Sterne (2003).

Table below shows the results of five controlled trials of three different drugs to lower cholesterol levels in middle-aged men and women considered to be at high risk of a heart attack. In each trial, patients were randomly assigned to receive either the drug (drug group) or an identical placebo (control group). Drugs $A$ and $B$ are relatively cheap, while drug $C$ is expensive. In each case cholesterol levels were measured after 1 year. The effects were measured by the difference in mean cholesterol between the drug and control groups. We will assume that a mean reduction of $40 \mathrm{mg} /$ decilitre confers substantial protection against subsequent heart disease, while a reduction of $20 \mathrm{mg} /$ decilitre confers model protection.

\begin{tabular}{ccccccc}
\hline Trial & $\begin{array}{c}\text { Drug } \\
\text { tested }\end{array}$ & $\begin{array}{c}\text { Number of } \\
\text { patients } \\
\text { per group }\end{array}$ & $\begin{array}{c}\text { Difference in } \\
\text { mean } \\
\text { cholesterol }^{*} \\
\text { (mg/decilitre })^{*}\end{array}$ & $\begin{array}{c}\text { Standard } \\
\text { error of } \\
\text { difference }\end{array}$ & $\begin{array}{c}95 \% \\
\text { confidence } \\
\text { interval for } \\
\text { difference }\end{array}$ & p-value \\
\hline 1 & A & 30 & -40 & 40 & -118.4 to 38.4 & 0.32 \\
2 & A & 3000 & -40 & 4 & -47.8 to -32.2 & $<0.001$ \\
3 & B & 40 & -20 & 33 & -84.7 to 44.7 & 0.54 \\
4 & B & 4000 & -2 & 3.3 & -8.5 to 4.5 & 0.54 \\
5 & C & 5000 & -5 & 2 & -8.9 to -1.1 & 0.012 \\
\hline
\end{tabular}

* when compared to control group

What can we infer from these five trials about the effect of the drugs in the population?

a) Drugs $A$ and $B$ are better than drug $C$.

b) Only drugs $A$ and $C$ are effective to reduce cholesterol levels.

c) Trial 3 excludes any possibility of benefit of drug $B$.

d) Although not have reached statistical significance, results from trial 1 are sufficient to show the benefit of drug $A$.

e) Items (a) and (d) are correct.

f) All alternatives are wrong.

Figure 3: Sample multiple-choice question for application of course concepts.

The question presented could be used in Phase 3 of TBL session. The main objectives is to make students learn some important concepts like "a large p-value does not mean that the null hypothesis is true " or "the medical importance of the estimated effect should be considered, even when there is good statistical evidence against the null hypothesis" and recognize the importance of evaluate the precision of the point estimates.

Many other alternatives can be formulated with the same example and teacher must predict possible discussion and misinterpretation.

\section{DISCUSSION}

Doctors are always forced to know statistical concepts, not only for their own research but also to critically read published papers which conduces their professional life. Reading scientific papers and conducting researches is part of the practice of Medicine and all other health professions, therefore, Biostatistics courses are highly necessary to help students to understand medical data and, after graduation, make decisions based on evidences from studies.

Despite of this, Brazilian undergraduate medical students usually dislike Statistics courses reporting them as too theoretical, boring, hard to follow and do not realize it would be useful and relevant for their careers. Part of this can be explained by the fact that statistics is taught separately from medical training. In most of faculties in Brazil, the problem become worst since Statistics is 
usually given only in the $1^{\text {st }}$ or $2^{\text {nd }}$ year, when students do not have enough background to understand this relevance. According to Astin et.al. (2002), statistics must be taught early in the undergraduate medical curriculum, but there is a need to reinforce its applicability throughout the course. Another point to mention is that some faculties in Brazil have been replacing statistics teachers by physicians with the excuse that the low popularity and inefficiency of statistics courses is due the fact they are taught by other faculty members of Mathematics and Statistics departments who emphasizes theory too much and have poor experience in medical problems. This is a comprehensible but dangerous choice since these courses can become superficial with serious conceptual mistakes because of lack of statistical knowledge of instructors.

It is clear that changes in teaching Statistics for medical students is an urgent need. Some educators have been trying develop courses more applied, based in real problems, efficient and enjoyable, but there is much to do and discuss about these proposed strategies.

In this work we discussed TBL, which has an increasing popularity among medical schools abroad. This is a recent methodology and the literature about using TBL in statistics courses for medical undergraduate students is practically null. Hagen et al (2012) conducted a study of undergraduate nursing's perceptions before and after an applied statistics course in TBL and conclude that although students have reported the change as positive, the agreement about relevance of statistics in their careers was only moderate. At the moment we did not find articles reporting evaluation of undergraduate medical students towards Statistics courses using TBL.

Limitations about TBL are very similar to other group-work methods, such as the time available or restrictions of the curriculum. A great number of teachers resist using groups, most of them worried about having a reliable and fair individual evaluation. The expression "work in groups" lead us to think that some poor students will be carried along by hard-work members. This is possible in the first TBL session, but according to Cestone et. al (2008) the grading system composed by $i R A T, g R A T$ and peer evaluation become students more engaged to better collaborate with the group and, as a consequence, improve their individual performance and develop interpersonal and team skills.

There are several difficulties in implementing new methodologies such as TBL in the medical curriculum. Particularly in Brazil, statistical courses in medical schools are very short and, sometimes, superficial, then it is difficult to elaborate a course with many TBL sessions. Another point to be mentioned is the volume of material that the students are requested to read. Teachers of all concurrent disciplines must be aligned and combine when TBL sessions occurs (for example, not more than three TBL sessions per week).

Implementing a TBL course must not be independent initiatives, but a collaborative work supported by the faculty members. Parmelee, et. al. have published an excellent practical guide where they discuss essential issues with regards to implementation of TBL including the institutional culture and students/faculty/teachers preparation. They suggest some previous useful steps such as training workshops and pilot TBL courses. My own experience as teacher of statistics says that one of the most problem is the lack of integration among teachers from different areas. Interdisciplinarity, contextualization and the truly synergy between teachers of statistics and medical education specialists are essential, not only for TBL, but any education strategy.

\section{CONCLUSION}

In summary, TBL seems to be positive and possible to be applied, maybe not as "pure TBL" but as a complement to traditional lectures. I expect that the main ideas of TBL can be used to improve teaching of Biostatistics in the sense of it stimulates discussion within and betweengroups, develops individual skills, induces students to be prepared before the classes and facilitates the connection between theory and practice. Besides, contextualized problems help to improve students awareness of the importance of medical statistics in medical practice.

There are few studies reporting students and teacher's perceptions about biostatistics courses in TBL. This is a future direction.

\section{REFERENCES}

Altman, D. (1991). Practical Statistics for Medical Research. London: Chapman \& Hall, 1991. 
Astin, J., Jenkins, T., \& Moore, L. (2002). Medical students'perspective on the teaching of medical statistics in the undergraduate medical curriculum. Statistics in Medicine, 21, 1003-1006.

Boyle, C. (1999). A Problem-Based Learning Approach to Teaching Biostatistics. Journal of Statistics Education, 7, http://www.amstat.org/publications/jse/secure/v7n1/boyle.cfm.

Brasil (2014). Diretrizes curriculares nacionais do curso de graduação em Medicina. Ministério da Educação/Conselho Nacional de Educação. http://portal.mec.gov.br/cne/arquivos/pdf/Med.pdf.

Cestone, C., Levine, R., \& Lane, D. (2008). Peer Assessment and Evaluation in Team-Based Learning. New directions for Teaching and Learning, no. 116. Published online in Wiley Interscience: www.interscience.wiley.com.

Hagen, B., Awosoga, O., Kellett, P., \& Dei, S. (2012). Evaluation of undergraduate nursing students's attitudes towards statitics courses, before and after a course in applied statistics. Title of the Journal where my article was publishedNurse Education Today, 33, 949-955.

Kirkwood, B., \& Sterne, J. (2003). Essential Medical Statistics (2nd edition). Oxford: Blackwell Science.

Michaelsen, L., Parmelee, D., McMahon, K., \& Levine, R. (2008). Team-based learning for health professions education: A guide to using small groups for improving learning. Sterling, VA: Stylus Publishing.

Parmelee, D., Michaelsen, L., Cook, S., \& Hudes, P. (2012). Team-based learning: a practical guide: AMEE Guide No. 65. Med Teach., 34(5), 275-87. 